\title{
ROLE OF OXIDATIVE STRESS IN TRAUMATIC BRAIN INJURY
}

\section{BY}

Amira A. El-gazar ${ }^{1}$, Azza Sayed Mohamed Awad ${ }^{2}$, Ebtehal El-demerdash ${ }^{3}$

FROM

${ }^{1}$ Pharmacology \& Toxicology Department, Faculty of Pharmacy, October 6 University

${ }^{2}$ Pharmacology \& Toxicology Department, Faculty of Pharmacy, Al-Azhar University

${ }^{3}$ Pharmacology \& Toxicology Department, Faculty of Pharmacy, Ain-Shams University

\begin{abstract}
Traumatic brain injury (TBI) is a worldwide health problem with oxidative stress recognized as a major pathogenetic factor, and leading cause of disability and death in young adults. The present experimental work was designed to study the role of oxidative stress in TBI. Mice were randomly classified into two groups (Sham group and TBI group, $\mathrm{n}=18 \mathrm{each})$. Mice were anaesthetized with chloralhydrate $(400 \mathrm{mg} / \mathrm{kg})$, after 24 hour of the surgery, the animals were killed by cervical dislocation, and brains were rapidly isolated and homogenized in saline, sham animals were subjected to same conditions without TBI. Traumatic brain injury group exhibited significant increment in lactate dehydrogenase (LDH), malondialdehyde (MDA) and prostaglandin E2 (PGE-2) contents as compared to sham group. Also, TBI group showed decrease in total antioxidant capacity (TAC) and systolic blood flow (SBF). TBI group showed focal gliosis detected in the cerebral cortex, associated with neuronal degeneration and diffuse gliosis in the striatum of the cerebrum. Based on our results, we concluded that, increasing oxidative stress plays an important role in TBI and decreasing it will offer neuroprotection to mice against TBI
\end{abstract}

Keywords: Traumatic brain injury, Oxidative stress, Antioxidants. 


\section{INTRODUCTION}

Traumatic brain injury (TBI) is one of the major healthcare concerns, constituting a major cause of death and disability throughout the world. Among the factors leading to TBI outcome are biochemical cascades which occur in response to primary and secondary injury. Where the primary injury which represents the direct mechanical damage, can not be therapeutically influenced, target of the treatment is the limitation of the secondary damage (delayed non-mechanical damage) (Werner and Engelhard, 2007a). These mechanisms or injuries generate oxidative stress, an imbalance between oxidant and antioxidant agents that can result in neural dysfunction and death (Rodriguez-Rodriguez et al., 2014). The mammalian brain is vulnerable to oxidative stress and so the reactive oxygen species (ROS) production because of high oxygen consumption needed for maintaining neuronal ion homeostasis during the propagation of action potentials. Interruption of mitochondrial function involves oxidative stress which leads to impaired energy production that leads to brain damage (Reiter, 1995). TBI is primarily and secondarily associated with a massive release of excitatory amino acid neurotransmitters, particularly glutamate (Bullock et al., 1998). This excess in extracellular glutamate availability affects neurons and astrocytes and results in over-stimulation of ionotropic and metabotropic glutamate receptors with consecutive $\mathrm{Ca}^{+} 2, \mathrm{Na}^{+}$, and $\mathrm{K}^{+}$-fluxes, triggering catabolic processes including bloodbrain barrier breakdown (Floyd $\boldsymbol{e t}$ al., 2005). The excess production of ROS will results in depletion of endogenous antioxidant system and that induces peroxidation of cellular and vascular structures, protein oxidation, cleavage of DNA, and inhibition of the mitochondrial electron transport chain, these mechanisms are adequate to contribute to immediate cell death and impairment of cerebral blood flow (Werner and Engelhard, 2007b), inflammatory processes and early or late apoptotic programs are induced by oxidative stress (Chong et al., 2005). The pathophysiology of TBI is presented in the weight drop model of TBI which uses the gravitational forces of a free falling weight to produce brain injury (Marmarou et $\boldsymbol{a l . ,}$ 1994; Flierl $\boldsymbol{e t}$ al., 2009). In view of this, the current work was conducted to study the role of oxidative stress in mouse model of traumatic brain injury.

\section{MATERIALS AND METHODS}




\section{Animals:}

Adult male albino mice with a body weight of 35-40 gm were used. Mice were obtained from the Nile Co. for Pharmaceutical and Chemical industries, Egypt. The animals were kept on a standard diet and water and palliated. The standard diet pellets (El-Nasr Co., Abu Zaabal, Egypt) contained not less than 20\% protein, 5\% fibers, 3.5\% fats, $6.5 \%$ ash and vitamins mixture. Animals were acclimatized for at least one week before commencement of experiments.

\section{Experimental protocol}

Thirty six albino mice were divided into two groups (18 per group) as follow: sham-operated group and TBI-operated group. The animal experiments described comply with the ethical principles and guidelines for the care and use of laboratory animals and the animal experimental protocol was approved by the Al-Azhar University Ethical Committee. 


\section{Induction of traumatic brain injury}

TBI was performed according to the study of Albert-Weißenberger et al. (2012) with some modifications. Mice were anaesthetized with chloralhydrate $(400 \mathrm{mg} / \mathrm{kg}$, IP). A midline longitudinal scalp incision was made and the skull was exposed. After identification of the right anterior frontal area $(1.5 \mathrm{~mm}$ lateral to the midline in the midcoronal plane) as impact area, a mouse was placed onto the platform directly under the weight drop device the weight was released and dropped with a final impact of $0.01 \mathrm{~J}$ onto the skull.

Mice were returned to cages immediately at the end of the surgical procedures where access to water and food is freely available. After 24 hour of the surgery, the animals were killed by cervical dislocation. Brains were rapidly isolated and washed with ice cold saline. The brains were homogenized in saline. Two brains per each group were fixed in $10 \%$ formalin for histological examination. Sham-operated animals were subjected to the same conditions without traumatic brain injury.

\section{Assessment of brain blood velocity}

Brain blood velocity was determined by using Doppler flowmetry (Bidop Esloov3, Hadeco, Kuwasaki, Japan). Cerebral perfusion of the mouse was monitored after the first hour after TBI. After a scalp incision, the probe was placed on the right $2 \mathrm{~mm}$ lateral and $3 \mathrm{~mm}$ posterior to the pregma. Perfusion was measured for $1 \mathrm{~min}$ for each mouse and the values were recorded (Pan et al., 2003) then the scalp wound was closed by slandered suture material (3-0 ethilon) and the wound area was treated with lidocaine cream.

\section{Biochemical analysis}

Several parameters were measured using suitable immunoassay ELISA kits as follows: lactate dehydrogenase (LDH) (Eiab,wuhan,china), malondialdehyde (MDA) (cell biolabs Inc., San Diego, California, USA), total antioxidant capacity (TAC) (cell biolabs Inc., San Diego, California, USA) and prostaglandin E2 (PGE-2) (CUSABIO Biotech Co., Wuhan, China).

\section{Histological assessment}


Two brains were taken from each group and fixed in $10 \%$ formaldehyde for 24hr. Washing was done in tap water then serial dilutions of alcohol were used for dehydration. Specimens were cleared in xylene and embedded in paraffin at $56^{\circ} \mathrm{C}$ in hot air oven for $24 \mathrm{hr}$. Paraffin bees wax tissue blocks were prepared for sectioning at 4 microns thickness by microtome. The obtained tissue sections were collected on glass slides, deparafinized, stained by hematoxylin \& eosin stain for routine examination using light electric microscope (Banchroft et al., 1996).

\section{Statistical analysis}

Differences between obtained values (means \pm SEM, $n=16$ ) were carried out by one way analysis of variance (ANOVA) followed by the Tukey's test for multiple comparison. A value of $p$ of 0.001 or less was taken as a criterion for a statistically significant difference. The data were analyzed with Graph Pad Prism software version5. 


\section{RESULTS}

Effect of traumatic brain injury on malondialdhyde (MDA) and total antioxidant capacity (TAC) in mice

Animals exposed to TBI showed a significant elevation in MDA as compared to sham group (52.38 \pm 0.79 vs. $32.38 \pm 0.79)$. Results showed a severe alteration in TAC activity in the group of animals that underwent TBI, TBI group showed a significant decrease in TAC by $29.3 \%$ as compared to sham group (Table 1 ).

Table (1): Effect of traumatic brain injury on malondialdhyde (MDA) and total antioxidant capacity (TAC)

\begin{tabular}{|l|l|l||}
\hline Groups & MDA $(\mathrm{nmol} / \mathrm{g})$ & TAC $(\mu \mathrm{mol} / \mathrm{g})$ \\
\hline Sham & $\mathbf{3 2 . 3 8} \pm \mathbf{0 . 7 9}$ & $\mathbf{3 7 . 6 3} \pm \mathbf{2 . 0 4}$ \\
\hline TBI & & \\
\hline
\end{tabular}

Values are expressed as means $\pm \operatorname{SEM}(n=16)$ a: Significant difference from sham at $\mathbf{p}<0.001$. Statistical analysis was carried out using one way ANOVA followed by Tukey's test for multiple comparisons.

2- Effect of traumatic brain injury on lactate dehydrogenase (LDH) and prostaglandin E2 (PGE-2) in mice:

Traumatic brain injury group exhibited significant increment in LDH activity (160.8 \pm 3.61 vs. $128.4 \pm 5.62)$ as compared to sham group. Also, TBI group showed a marked elevation in PGE-2 content $(42.92 \pm 1.12$ vs. $31.76 \pm 1.32)$ as compared to control group (Table 2).

Table (2): Effect of traumatic brain injury on Lactate dehydrogenase (LDH) and prostaglandin E2 (PGE-2) in mice: 


\begin{tabular}{|l|l|l|}
\hline Group & LDH (U/g tissue) & PGE-2 (ng/g tissue) \\
\hline Sham & $\mathbf{1 2 8 . 4} \pm \mathbf{5 . 6 2}$ & $\mathbf{3 1 . 7 6} \pm \mathbf{1 . 3 2}$ \\
\hline TBI & $\mathbf{1 6 0 . 8} \pm \mathbf{3 . 6 1}^{\mathrm{a}}$ & $\mathbf{4 2 . 9 2} \pm \mathbf{1 . 1 2}^{\mathrm{a}}$ \\
& & \\
\hline
\end{tabular}

Values are expressed as means $\pm \operatorname{SEM}(n=16)$ a: Significant difference from sham at $\mathbf{p}<0.001$. Statistical analysis was carried out using one way ANOVA followed by Tukey's test for multiple comparisons.

3- Effect of traumatic brain injury on systolic blood flow (SBF) in mice:

TBI group showed a marked decrease in systole $(3.02 \pm 0.19)$ as compared to sham group $(6.33 \pm \mathbf{0 . 6 3})$ (Table 3$)$.

Table (3): Effect of traumatic brain injury on systolic blood flow (SBF)

\begin{tabular}{|l|l||}
\hline Group & $\mathrm{SBF}(\mathrm{cm} / \mathrm{min})$ \\
\hline Sham group & $\mathbf{6 . 3 3} \pm \mathbf{0 . 6 3}$ \\
\hline TBI group & $\mathbf{3 . 0 2} \pm \mathbf{0 . 1 9}$ \\
\hline
\end{tabular}

Values are expressed as means $\pm \operatorname{SEM}(n=16)$ a: Significant difference from sham at $\mathbf{p}<0.001$. Statistical analysis was carried out using one way ANOVA followed by Tukey's test for multiple comparisons.

\section{Histopathology}

Brain samples obtained from sham-operated group showed normal histological structure of the meninges, cerebral cortex, striatum of the cerebrum and cerebellum (Figure 1A). On the other hand, TBI group showed focal gliosis in the cerebral cortex, associated with neuronal degeneration and diffuse gliosis in the striatum of the 
cerebrum. Also, focal hemorrhage was noticed in the encephalomalacia of the striatum and in the fissure between the gliosis and encephalomalacia of the hippocampus and the striatum (Figure 1B).
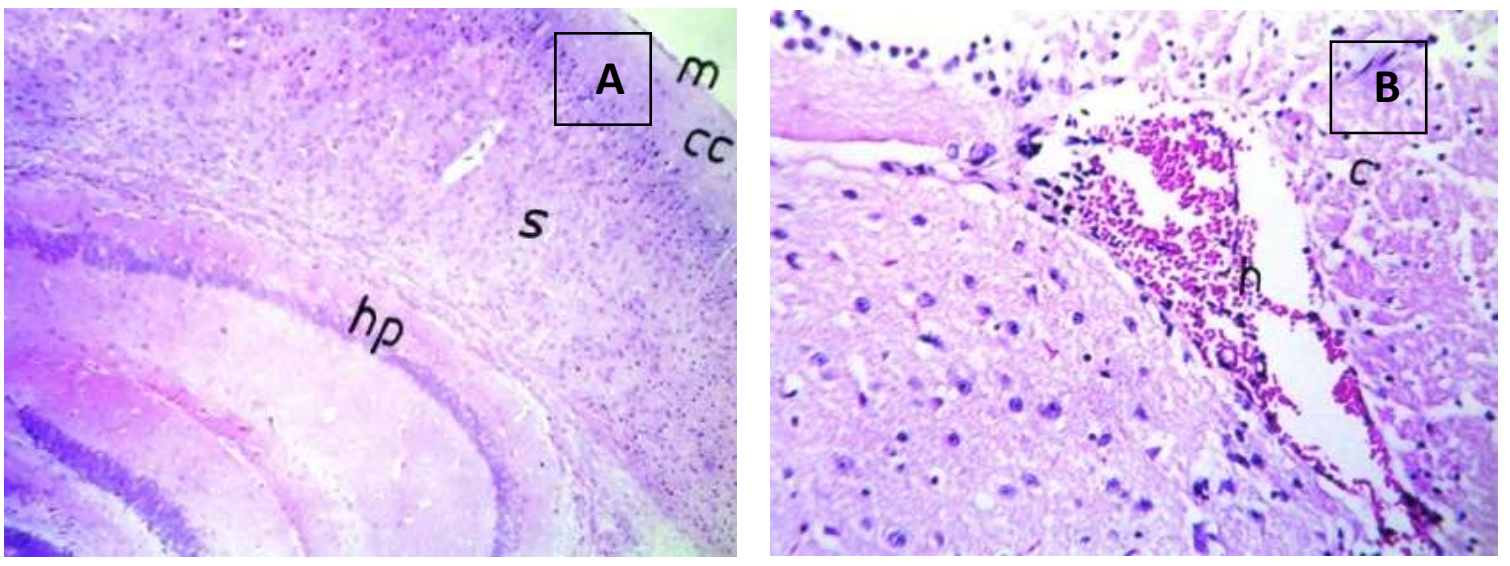

Figure 1: Photographs showing histopathological examination of the mice brain in different groups using H\&E (x 40). A: Brain of mouse in sham-operated group shows normal histological structure of the meanings (m), cerebral cortex (cc), striatum of the cerebrum (s) and hippocampus (hp). B: Brain of mouse in TBI group showing hemorrhage in the fissure (h) with encephalomalacia and gliosis (c) in hippocampus.

\section{DISCUSSION}

The ROS production after trauma is believed to be due to multiple events such as increased intracellular $\mathrm{ca}^{+} 2$, excitotoxicity, phospholipids degradation and mitochondrial dysfunction causing an overload of endogenous free radical scavenging systems and then their depletion in the injured tissue (Atlante et al., 2001; Bayir et al., 2002). If lipid peroxidation not stopped it will progress over the surface of the cell membrane causing damage to phospholipids dependent enzymes, disruption of ionic gradients and even blood brain barrier lysis (LeBel and Bondy, 1991) for that reasons ROS inhibition and decreasing oxidative stress have been proposed as possible treatment for TBI as curcumin that was able to counteract the outcome of traumatic brain injury on oxidative stress, synaptic plasticity (Wu et al., 2006). The degree of lipid peroxidation can be assessed by measurement of MDA content as oxidative stress generates ROS that attack the membrane lipids resulting in the formation of MDA (Srinivasan and Pugalendi, 2000). Concentration of MDA, constituting the final product of arachidonic acid cascade, represents the exponent of lipid peroxidation dynamics and of cell membrane injury. The significant severity of cell membrane destruction in the brain is detected by MDA measurements in the cerebrospinal fluid, has been noted in cases with multiple and chronic intracerebral hematomas. As a result to the TBI related ROS and free radicals (FRs) formation, lipid peroxidation level was significantly increased in brain tissue in the present study, a finding that was documented in previous works (Ates et al., 2007; Menku et al., 2010; Kalayci et al., 2011). 
Antioxidants inhibit lipid peroxidation by preventing the peroxidative chain reaction and picking up the reactive-oxygen derivatives (Kalayci et al., 2011), but overproduction of ROS may deplete endogenous antioxidants. The formation or distribution of free oxygen radicals should be decreased to enable the fixing of poor neurological outcomes and to prevent neuronal damage secondary to ischemia after trauma (Ates et al., 2007). It is assumed that the antioxidant defense system cannot completely neutralize the free oxygen radicals occurring in ischemic tissues (Halliwell, 1992). Agents inhibiting free oxygen radicals have also been reported to improve poor neurological outcomes in the central nervous system after trauma or ischemia by their therapeutic effects (Leibovitz and Siegel, 1980; Ates et al., 2007).

Lactate dehydrogenase is a cytoplasmic enzyme present in brain, is released into the blood when the brain is injured, and the rise of its serum level indicates the degree of brain damage (Rao et al., 1978). It was concluded that measurement of serum LDH can be used effectively in the management of head injury by indicating the extent and type of brain damage at an early stage and in assessing the prognosis (Thomas and Rowan, 1976). The current study showed that TBI by weight drop model is cytotoxic on brain and that was clear from the results of LDH in comparison with sham group.

Trauma to the brain can activate several inflammatory pathways that involves the release of arachidonic acid from cellular phospholipids by cytosolic phospholipase A2 (PLA2), and its subsequent cyclooxygenation to form prostaglandin E2 (PGE2) (Pooler et al., 2004). Excessive activation of PLA2 may induce membrane phospholipids degradation, accumulation of proinflammatory mediators and then result in lipid peroxidation and neuronal cell death (Farooqui et al., 1999; Farooqui et al., 2006) supporting that a previous study has shown that a close brain injury can induce PLA2 activation and subsequent production of prostaglandin E2, a proinflammatory mediator, in rats (Shohami et al., 1989), controlled cortical injury in rats is followed by membrane phospholipids degeneration and free fatty acid release (Dhillon et al., 1994; Homayoun et al., 1997) and brain injury in human also results in increased free fatty acid in CSF (Pilitsis et al., 2003). Our results showed increment increase in PGE-2 after induction of trauma in comparison with sham operated.

Because neurological deterioration after TBI relates to cerebral ischemia, several studies have successfully used transcranial Doppler (TCD) and laser Doppler flometry as a bedside tool to investigate changes in cerebral hemodynamics, primarily in the intensive care unit (ICU) clinically and on experimental animal studies on TBI (Pan et al., 2003; White and Venkatesh, 2006). In our study we used Doppler one hour after trauma to determine changes in cerebral blood flow by means of systolic blood flow, we observed great reduction in SBF in TBI group in comparison with sham one, and that in agreement with animal studies that have shown mild TBI to elicit a significant decrease in regional CBF $1 \mathrm{~h}$ after mild brain injury (Golding et al., 1999).

\section{REFERENCES}

Albert-Weißenberger C, Várrallyay C, Raslan F, Kleinschnitz C and Sirén A-L (2012). An experimental protocol for mimicking pathomechanisms of traumatic brain injury in mice. Exp Transl Stroke Med 4:6.

Ates O, Cayli S, Altinoz E, Gurses I, Yucel N, Sener M, et al. (2007). Neuroprotection by resveratrol against traumatic brain injury in rats. Mol Cell Biochem 294(1-2): 137-144. 
Atlante A, Calissano P, Bobba A, Giannattasio S, Marra E and Passarella S (2001). Glutamate neurotoxicity, oxidative stress and mitochondria. FEBS Lett 497(1): $1-5$.

Bayir H, Kagan VE, Tyurina YY, Tyurin V, Ruppel RA, Adelson PD, et al. (2002). Assessment of antioxidant reserves and oxidative stress in cerebrospinal fluid after severe traumatic brain injury in infants and children. Pediatr Res 51(5): 571-578.

Banchroft, J. D., Stevens, A., Turner, D. R. (1996) Theory and Practice of Histological Technique.4th ed., Churchill Livingston, N.Y., London, San Francisco, Tokyo.

Bullock R, Zauner A, Woodward JJ, Myseros J, Choi SC, Ward JD, et al. (1998). Factors affecting excitatory amino acid release following severe human head injury. J Neurosurg 89(4): 507-518.

Chong ZZ, Li F and Maiese K (2005). Oxidative stress in the brain: novel cellular targets that govern survival during neurodegenerative disease. Prog Neurobiol 75(3): 207-246.

Dhillon HS, Donaldson D, Dempsey RJ and Prasad MR (1994). Regional levels of free fatty acids and Evans blue extravasation after experimental brain injury. $J$ Neurotrauma 11(4): 405-415.

Farooqui AA, Litsky ML, Farooqui T and Horrocks LA (1999). Inhibitors of intracellular phospholipase A2 activity: their neurochemical effects and therapeutical importance for neurological disorders. Brain Res Bull 49(3): 139-153.

Farooqui AA, Ong WY and Horrocks LA (2006). Inhibitors of brain phospholipase A2 activity: their neuropharmacological effects and therapeutic importance for the treatment of neurologic disorders. Pharmacol Rrev 58(3): 591-620.

Flierl MA, Stahel PF, Beauchamp KM, Morgan SJ, Smith WR and Shohami E (2009). Mouse closed head injury model induced by a weight-drop device. Nat Protoc 4(9): 1328-1337.

Floyd CL, Gorin FA and Lyeth BG (2005). Mechanical strain injury increases intracellular sodium and reverses $\mathrm{Na}^{+} / \mathrm{Ca}^{2+}$ exchange in cortical astrocytes. Glia 51(1): 35-46.

Golding EM, Steenberg ML, Contant CF, Jr., Krishnappa I, Robertson CS and Bryan RM, Jr. (1999). Cerebrovascular reactivity to $\mathrm{CO}(2)$ and hypotension after mild cortical impact injury. Am J Physiol 277(4 Pt 2): H1457-H1466.

Halliwell B (1992). Reactive oxygen species and the central nervous system. In: Free Radicals in the Brain. pp 21-40: Springer.

Homayoun P, Rodriguez de Turco EB, Parkins NE, Lane DC, Soblosky J, Carey ME, et al. (1997). Delayed phospholipid degradation in rat brain after traumatic brain injury. J Neurochem 69(1): 199-205.

Kalayci M, Unal MM, Gul S, Acikgoz S, Kandemir N, Hanci V, et al. (2011). Effect of coenzyme Q10 on ischemia and neuronal damage in an experimental traumatic brain-injury model in rats. BMC Neurosci 12: 75. 
LeBel CP and Bondy SC (1991). Oxygen radicals: common mediators of neurotoxicity. Neurotoxicol Tteratol 13(3): 341-346.

Leibovitz BE and Siegel BV (1980). Aspects of free radical reactions in biological systems: aging. J Gerontol 35(1): 45-56.

Marmarou A, Foda MA, van den Brink W, Campbell J, Kita $H$ and Demetriadou K (1994). A new model of diffuse brain injury in rats. Part I: Pathophysiology and biomechanics. J Neurosurg 80(2): 291-300.

Menku A, Ogden M and Saraymen R (2010). The protective effects of propofol and citicoline combination in experimental head injury in rats. Turk Neurosurg 20(1): 57-62.

Pan W, Kastin AJ, Rigai T, McLay $R$ and Pick CG (2003). Increased hippocampal uptake of tumor necrosis factor alpha and behavioral changes in mice. Exp Brain Res 149(2): 195-199.

Pilitsis JG, Coplin WM, O'Regan MH, Wellwood JM, Diaz FG, Fairfax MR, et al. (2003). Measurement of free fatty acids in cerebrospinal fluid from patients with hemorrhagic and ischemic stroke. Brain Res 985(2): 198-201.

Pooler AM, Arjona AA, Lee RK and Wurtman RJ (2004). Prostaglandin E2 regulates amyloid precursor protein expression via the EP2 receptor in cultured rat microglia. Neurosci Lett 362(2): 127-130.

Rao C, Shukla P, Mohanty S and Reddy Y (1978). Predictive value of serum lactate dehydrogenase in head injury. J Neurol Neurosurg Psychiatry 41(10): 948953.

Reiter RJ (1995). Oxidative processes and antioxidative defense mechanisms in the aging brain. FASEB J 9(7): 526-533.

Rodriguez-Rodriguez A, Jose Egea-Guerrero J, Murillo-Cabezas F and CarrilloVico A (2014). Oxidative stress in traumatic brain injury. Curr Med Chem 21(10): 1201-1211.

Shohami E, Shapira Y, Yadid G, Reisfeld N and Yedgar S (1989). Brain phospholipase A2 is activated after experimental closed head injury in the rat. J Neurochem 53(5): 1541-1546.

Srinivasan KN and Pugalendi KV (2000). Effect of excessive intake of thermally oxidized sesame oil on lipids, lipid peroxidation and antioxidants' status in rats. Ind J Exp Biol 38(8): 777-780.

Thomas DG and Rowan TD (1976). Lactic dehydrogenase isoenzymes following head injury. Injury 7(4): 258-262.

Werner C and Engelhard K (2007a). Pathophysiology of traumatic brain injury. $\mathrm{Br} J$ Anaesth 99(1): 4-9.

Werner C and Engelhard K (2007b). Pathophysiology of traumatic brain injury. $\mathrm{Br} J$ Anaesth 99(1): 4-9.

White $\mathbf{H}$ and Venkatesh B (2006). Applications of transcranial Doppler in the ICU: a review. Intensive Care Med 32(7): 981-994. 
Wu A, Ying $Z$ and Gomez-Pinilla $F$ (2006). Dietary curcumin counteracts the outcome of traumatic brain injury on oxidative stress, synaptic plasticity, and cognition. Exp Neurol 197(2): 309-317.

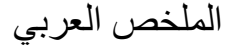

$$
\begin{aligned}
& \text { دور الإجهاد التأكسدى فى الاصابات الاماغية }
\end{aligned}
$$

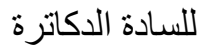

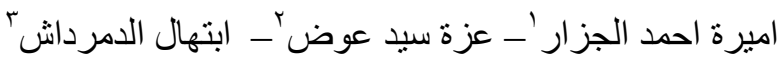

$$
\begin{aligned}
& \text { قسم الادوية و السموم كلية الصيدلة_ جامعة السادس من اكتوبر } \\
& \text { قسم الادوية و السموم كلية الصيدلة (بنات بالقاهرة )- جامعة الاز هر؟ }
\end{aligned}
$$

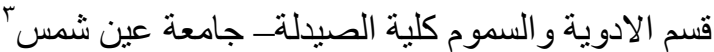

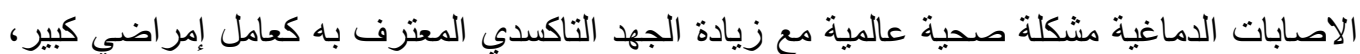

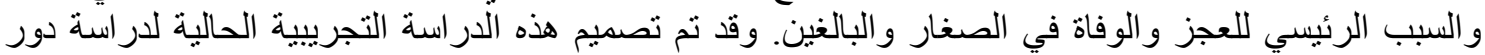

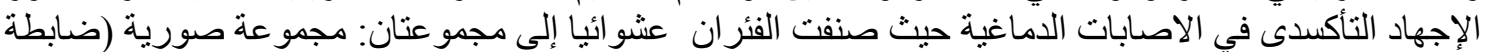

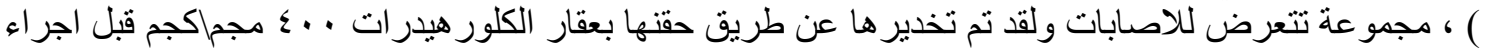

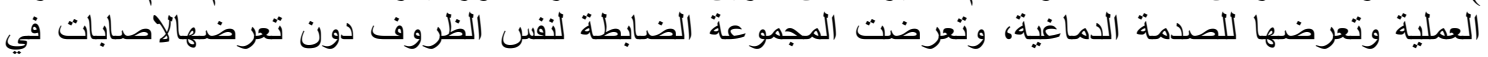

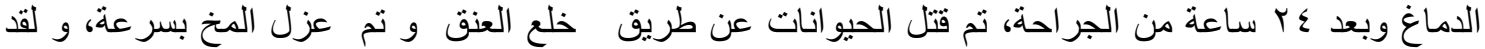

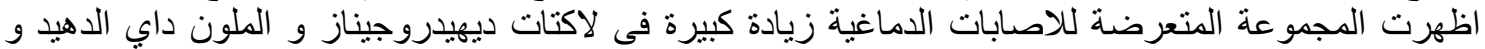

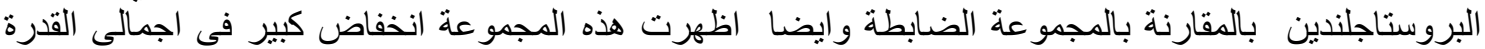

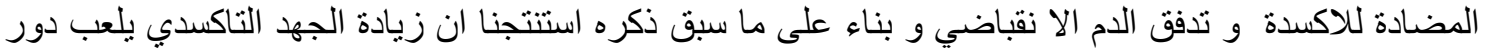
هام فى الصدمات الدماغية ولة لاضة اضر الار كبيرة. 